\title{
The Incidence of Acute Kidney Injury after Coronary Artery Bypass Surgery with or without Cardiopulmonary Bypass
}

\author{
Seyed Tayeb Moradian, ${ }^{1}$ Abbas Ebadi, ${ }^{2}$ Fakhraddin Faizi, ${ }^{3}$ Mohammad Hasan Kalantar Motamedi, \\ and Mohammad Saeid Ghiasi ${ }^{5, *}$ \\ ${ }_{1}^{1}$ (STM), PhD, Assistant Professor, Nursing Faculty, Baqiyatallah University of Medical Sciences, Tehran, IR Iran \\ ${ }^{2} \mathrm{PhD}$, School of Nursing, Baqiyatallah University of Medical Sciences, Tehran, IR Iran \\ ${ }^{3}$ MSc, School of Nursing, Baqiyatallah University of Medical Sciences, Tehran, IR Iran \\ ${ }^{4}$ Associated Professor, Cardiac Surgeon, Baqiyatallah University of Medical Sciences, Tehran, IR Iran \\ ${ }^{5}$ (SMSGH), MD, Cardiac Anesthesiology Fellowship, Baqiyatallah University of Medical Sciences, Tehran, IR Iran \\ "Corresponding author: Mohammad Saeid Ghiasi, MD, Cardiac Anesthesiology Fellowship, Baqiyatallah University of Medical Sciences, Tehran, IR Iran. Tel: +98-9123781448, \\ E-mail: t.moradyan@yahoo.com
}

Received 2016 October 01; Revised 2016 October 15; Accepted 2016 November 20.

\begin{abstract}
Background: The incidence of acute kidney injury commonly follows cardiac surgery. Some studies have demonstrated better outcomes following off-pump cardiac surgery.

Objectives: This study was conducted to compare the incidence of acute kidney injury and laboratory findings in patients undergoing cardiac surgery with or without cardiopulmonary bypass.

Methods: In a retrospective study, 167 patients who underwent coronary artery bypass grafts (CABG) with or without cardiopulmonary bypass were selected by systematic randomized sampling method from the list of Jamaran heart hospital (Tehran) patients and the incidence of acute kidney injury and laboratory findings were compared.

Results: There was no significant difference in the demographics (age, sex, drug history, and chronic disease) between the groups $(\mathrm{P}>0.05)$. The acute kidney injury (AKI) was observed in 19.3 and $33.7 \%$ of the off-pump and on-pump patients, respectively. A total number of16 (19.3\%) in the off-pump and 44 (52.9\%) in on-pump group needed blood transfusion. The mean hospital stay was $6.74 \pm$ 1.86 days for OPCAB and $7.2 \pm 1.72$ for on-pump patients. Haemoglobin and haematocrit level, also, were higher in OPCAB.

Conclusions: This study showed that off-pump coronary artery bypass (OPCAB) is superior in acute kidney injury, blood transfusion, blood glucose management, and hospital stay. Considering these complications and those adverse effects, it seems that off-pump technique is better in selected patients, but it is proposed that more prospective multi-disciplinary studies with larger sample sizes should be done.
\end{abstract}

Keywords: Coronary Arteries Bypass Surgery, Acute Kidney Injury, Cardiopulmonary Bypass, Laboratory Findings

\section{Background}

Acute kidney injury (AKI) is a common complication following coronary artery bypass graft (CABG). Based on different definitions of acute renal failure, the incidence of ARF after CABG varies from $6.9 \%$ to $42.5 \%(1,2)$. Some studies have reported AKI in half of the cardiac surgical patients (3). Age, hypertension, NYHA class, diabetes, cardiopulmonary bypass time, redo operation, ejection fraction, and the haematocrit level are considered as some risk factors of AKI $(4,5)$. Previous studies have demonstrated that only a slight increase in Creatinine level is related to an increased mortality and morbidity after $\operatorname{CABG}(6,7)$. Some studies have reported that the AKI is linked to the activated inflammatory process during the surgery (8). As we know the CPB is the most important source of the inflammation in cardiac surgery. So, some studies believe that the CPB is a risk factor for AKI and the elimination of $\mathrm{CPB}$ reduces the inflammation and AKI $(4,9)$. Studies have demonstrated that the incidence of AKI is higher in the on-pump group $(10,11)$, but others have reported no difference between the AKI in the on-pump and the off-pump patients (3). Based on the available data the need for more research in the field of AKI is inevitable (12). Nurses have an important role in diagnosing and preventing the complications following cardiac surgery. They also start the first line care and therapeutic measures in the field of life threatening complications $(13,14)$.

Off-pump coronary artery bypass grafting (OPCAB) is, increasingly, going to be as a gold standard for coronary arteries revascularization (15). The old but newly approached technique lowers the operational complications arising from using cardio-pulmonary bypass (CPB) machine (16). In the recent years, this method has even had better outcomes in complicated patients (17). One of the most alleged concerns of the new technique is the bad quality of 
the grafts which reduce the surgery outcomes, but reports have shown that the 10-year outcome was similar to convenience coronary artery bypass grafts (CCABG) $(18,19)$. Morbidity, need for blood transfusion, re-operation for bleeding, need for long term mechanical ventilation, ICU, and hospital stay is lower in the $\operatorname{OPCAB}(9,20,21)$.

Blood transfusion is one of the most important problems after CABG; patients who had received blood had longer extubation time, ICU and hospital stay, higher mortality and morbidity, and operational complications (22, 23). Previous studies have shown that anaemia is more prevalent than other surgeries in cardiac surgery (24). Another problem following CABG is hyperglycaemia which is related to decreased operational outcomes in the long run and increased mortality and morbidity after CABG (25, 26). Hyperglycaemia after CABG has been observed in the non-diabetic patients (27). Long-term hospitalization and AKI, also, are higher in diabetic patients undergoing coronary artery bypass grafting $(4,28)$. Studies imply that onpump patients have higher post-operative blood glucose levels (29). Considering the importance of the complication management and the lapse of several decades of the introduction of CABG in Iran and the increased use of OP$\mathrm{CAB}$, still few qualified studies comparing the outcomes of the patients who are undergoing CABG with and without СРB have been done in the country, so we conducted this study to compare the laboratory findings in patients who underwent $\mathrm{CABG}$ with or without using $\mathrm{CPB}$.

\section{Methods}

In a retrospective study, 167 patients who underwent CABG with or without cardiopulmonary bypass were studied. First, the list of the patients who underwent CABG in the last 6 months of 2009 in Jamaran heart hospital was obtained from the medical records department. Among the total number of 497 patients, 85 patients (17\%) without СРB and 412 patients (83\%) have been operated using СРB. The exclusion criteria were simultaneously valve surgery, redo CABG, and carotid endarterectomy. A total number of 83 patients from off-pump and 336 patients from on-pump group met the inclusion criteria, then by using the systematic randomized sampling method, 84 patients from the on-pump group and 83 patients from the off-pump group were selected, enrolled, and studied. Haematological and biochemical laboratory tests, bleeding from drains, need for blood transfusion, hospital and ICU stay were compared. The patients had been operated by three experienced surgeons and according to the surgeon's decision it had been with or without $\mathrm{CPB}$. Surgical access to hearts was done by mid-sternotomy under general anaesthesia. Incision and suturing techniques were similar in both groups.
In all patients, left internal mammary graft was used and in the conditions needing more than one graft, saphenous vein was applied. Based on the hospital policy, routine laboratory tests were checked for all the patients before the surgery, if patients had high blood glucose, insulin therapy was initiated and if creatinine level was higher than $1.4 \mathrm{mg} / \mathrm{dL}$ nephrology consultation was done. After the surgery, all the patients were transferred to the ICU and, then, laboratory tests were checked as a routine. ICU admission, 24 hours after surgery and discharge laboratory findings were collected. Patient's blood glucose was controlled by intravenous regular insulin in ICU and oral hypoglycaemic agents and subcutaneous insulin in post ICU ward. Blood transfusion was done as ICU and surgeon's protocols based on haemoglobin and haematocrit levels. We applied the recent definition that $0.3 \mathrm{mg} / \mathrm{dL}$ increase in Creatinine level from the baseline value is an AKI (30). Data were analysed using SPSS version 17 software. Parametric continuous data are expressed as mean (SD), nonparametric data are presented as median (interquartile range) and categorical data as number (\%). Independent ttest, Mann-Whitney U and chi square, and fisher exact tests were used to analyze the data. P-value less than 0.05 was considered statistically significant.

\section{Results}

There was no significant statistical difference in the demographic factors (age, sex, previous medical history, and chronic diseases) between the groups (Table 1). One patient in the on-pump group died due to low cardiac output, inappropriate response to inotrope agents, intraAortic Balloon-pump (IABP), and then multi organ failure. Haemoglobin and haematocrit levels were higher in the off-pump group. A total number of 16 (19.3\%) in off-pump and 44 (52.9\%) in on-pump groups needed blood transfusion which was a statistically significant difference. The incidence of AKI 24 hours after the surgery was, significantly, raised in the on-pump group (33.7\% vs 19.4\%). At discharge time, still $12 \%$ of OPCAB and $15.7 \%$ on-pump patients had acute renal failure, but it wasn't significant. Haemodialysis was performed for one patient in the on-pump group due to acute renal failure. There were exceptions of high creatinine level and blood glucose in the on-pump 24 hours after the surgery, but other values were similar in ICU admission and hospital discharge measurements (Table 2). The 24 hour Post-operation creatinine level was significantly raised in comparison to the ICU entrance measurements, but this amount was about normal values at discharge from Hospital, there was no significant difference in the creatinine changes' trend between the groups (Figure 1). 
Table 1. The Comparison between the Groups in the Demographic Information ${ }^{\mathrm{a}}$

\begin{tabular}{lccc}
\hline Variable & Off-Pump & On-Pump & P Value \\
\hline Total & 83 & 84 & 0.99 \\
\hline Number of females & 32.5 & 32.1 & 0.99 \\
\hline Age & $62.4 \pm 10.4$ & $61.14 \pm 9.4$ & $0 / 39$ \\
\hline Baseline ejection fraction & $49.8 \pm 9.8$ & $48.2 \pm 10.4$ & 0.30 \\
\hline Diabetes & 33.7 & 44 & 0.20 \\
\hline Hypertension & 56.6 & 61.9 & 0.53 \\
\hline Hyperlipidemia & 48.2 & 50 & 0.87 \\
\hline Smoker & 19.3 & 17.9 & 0.84 \\
\hline CVA & 2.4 & 3.6 & 0.44 \\
\hline Family history & 2.4 & 6 & 0.44 \\
\hline
\end{tabular}

Abbreviation: CVA, cerebro-vascular accident.

${ }^{\mathrm{a}}$ Values are expressed as mean $\pm \mathrm{SD}$ or No. (\%).

Table 2. The Comparison between the Groups in Our Study Variables

\begin{tabular}{|lccc|}
\hline Variable & Off Pump & On Pump & P Value \\
\hline ICU entrance Hb & $10.4 \pm 1.39$ & $10.2 \pm 0.98$ & $0.04^{*}$ \\
\hline 24 hr after surgery Hb & $9.96 \pm 1.14$ & $9.5 \pm 1.09$ & $0.01^{*}$ \\
\hline Discharge Hb & $10.8 \pm 1.31$ & $10.18 \pm 1.16$ & $0.001^{*}$ \\
\hline ICU entrance HCT & $31.3 \pm 3.77$ & $30.09 \pm 3.19$ & $0.05^{*}$ \\
\hline 24 after surgery HCT & $30.42 \pm 3.77$ & $29.01 \pm 3.08$ & $0.006^{*}$ \\
\hline Discharge HCT & $32.8 \pm 3.82$ & $30.77 \pm 3.69$ & $0.001^{*}$ \\
\hline ICU entrance BS & $176.9 \pm 56.1$ & $201.02 \pm 52.2$ & $0.005^{*}$ \\
\hline 24 after surgery BS & $160.3 \pm 48.9$ & $186.03 \pm 57.4$ & $0.002^{*}$ \\
\hline Discharge BS & $131.7 \pm 50.9$ & $149.03 \pm 62.9$ & $0.04^{*}$ \\
\hline Acute kidney injury, \% & 19.3 & 33.7 & $0.04^{*}$ \\
\hline ICU entrance Cr & $0.92 \pm 0.21$ & $1.01 \pm 0.47$ & 0.29 \\
\hline 24 after surgery Cr & $1.02 \pm 0.27$ & $1.17 \pm 0.47$ & $0.03^{*}$ \\
\hline Discharge Cr & $1 \pm 0.03$ & $1.08 \pm 0.047$ & 0.74 \\
\hline ICU stay & $2.37 \pm 0.85$ & $2.42 \pm 1.067$ & 0.87 \\
\hline Hospital stay & $6.74 \pm 1.86$ & $7.2 \pm 1.72$ & $0.008^{*}$ \\
\hline Abbrevations:Hb & & & \\
\hline
\end{tabular}

Abbreviations: Hb, hemoglobin, HCT, hematocrit; BS, blood sugar; Cr, creatinin.

\section{Discussion}

In the study, AKI was higher in the on-pump patients who underwent coronary revascularization; accordant to Di Mauro (2007), reported acute renal failure significantly reduced post-operatively in the off-pump patients (31). Avoiding cardiopulmonary bypass as a renoprotective factor reduces Kidney Injury during CABG stated by Abu-omar (32). Post-operative increase of creatinine in the on-pump vs the off-pump in the study is supported by Hix JK et al.

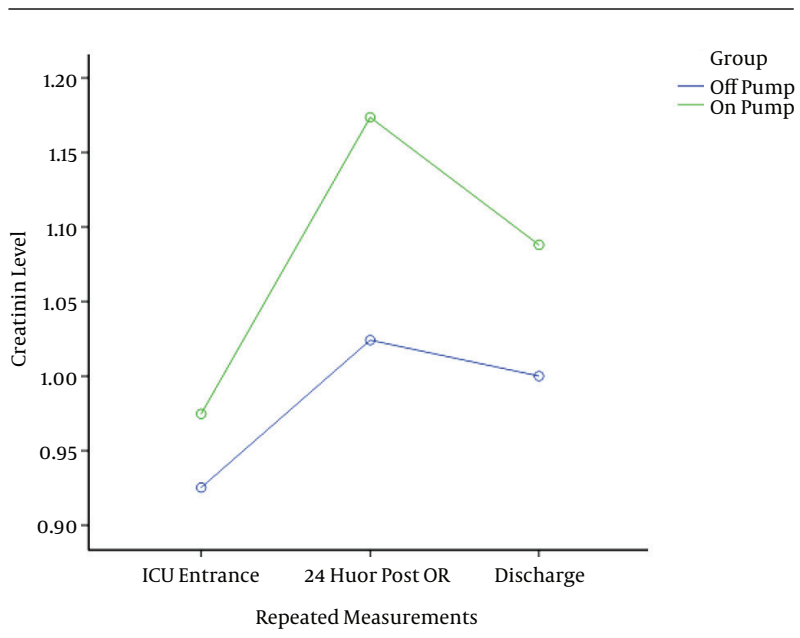

Figure 1. Creatinine Changes Trend

(2006) who have reported that AKI in off-pump reduced to $50 \%$ (1.2\% vs $2.5 \%)$ in comparison with on-pump group (11). A reduction in the renal insufficiency, ICU and hospital stay, and blood transfusion in OPCAB group in comparison with CCABG were, also, reported by Kerendi, F (2008) (33). No significant difference was seen in the ICU stay in our study in both groups, discordant to Kerendi, F (2008), Hussain, I (2008), and Lamy, A (2005) findings (34, 35). Increased post-operative blood glucose level in the on-pump subjects noted in the study can increase the comorbidity rate (36). Increased blood glucose is more associated with CCABG than beating heart coronary revascularization (37). Blood transfusion has been introduced as an operation outcome reducer (38). Studies show that blood transfusion is higher in on-pump patients (39), we have similar results. But, using $\mathrm{CPB}$ is not related significantly to increased RBC infusion in CABG (21). In the present study, hospital stay was higher in the on-pump group, but ICU stay was similar between the groups, we have similar results of hospital stay with some of the studies (40), but our results were different from Guler's study (41).

In this study, creatinine was the only criterion for defining AKI, but the recent data shows that creatinine is not a good marker for rapid detection of AKI. It is, also, affected by hemodilution protocols.

This study showed that OPCAB is superior in blood transfusion, acute kidney injury, blood glucose management, and hospital stay. Considering these complications and those adverse effects, it seems that off-pump technique is a better technique in the selected patients, but it is proposed that prospective, multi central studies with larger sample sizes should be done. 


\section{Acknowledgments}

The authors sincerely thank the managers and the staff of Jamaran heart hospital, especially the nurses in the ICU and the internal heart wards for their cooperation and assistance in different phases of the study.

\section{Footnote}

Conflict of Interest: The authors do not have any conflict of interest.

\section{References}

1. Dasta JF, Kane-Gill SL, Durtschi AJ, Pathak DS, Kellum JA. Costs and outcomes of acute kidney injury (AKI) following cardiac surgery. Nephrol Dial Transplant. 2008;23(6):1970-4. doi: 10.1093/ndt/gfm908. [PubMed: 18178605].

2. Lombardi R, Ferreiro A. Risk factors profile for acute kidney injury after cardiac surgery is different according to the level of baseline renal function. Ren Fail. 2008;30(2):155-60. doi: 10.1080/08860220701808129. [PubMed: 18300114].

3. Reents W, Hilker M, Borgermann J, Albert M, Plotze K, Zacher M, et al. Acute kidney injury after on-pump or off-pump coronary artery bypass grafting in elderly patients. Ann Thorac Surg. 2014;98(1):9-14. doi: 10.1016/j.athoracsur.2014.01.088. [PubMed: 24881861] discussion 14-5.

4. Yi Q, Li K, Jian Z, Xiao YB, Chen L, Zhang Y, et al. Risk Factors for Acute Kidney Injury after Cardiovascular Surgery: Evidence from 2,157 Cases and 49,777 Controls - A Meta-Analysis. Cardiorenal Med. 2016;6(3):23750. doi: 10.1159/000444094. [PubMed: 27275160].

5. Onk OA, Onk D, Ozcelik F, Gunay M, Turkmen K. Risk Factors for Acute Kidney Injury after Coronary Artery Bypass Surgery and Its Detection Using Neutrophil Gelatinase-Associated Lipocalin. Cardiorenal Med. 2016;6(3):216-29. doi: 10.1159/000444099. [PubMed: 27275158].

6. Bojan M, Basto Duarte MC, Ermak N, Lopez-Lopez V, Mogenet A, Froissart M. Structural equation modelling exploration of the key pathophysiological processes involved in cardiac surgery-related acute kidney injury in infants. Crit Care. 2016;20(1):171. doi: 10.1186/s13054-0161350-1. [PubMed: 27262736].

7. Aronson S, Fontes ML, Miao Y, Mangano DT, Investigators of the Multicenter Study of Perioperative Ischemia Research G, Ischemia R, et al. Risk index for perioperative renal dysfunction/failure: critical dependence on pulse pressure hypertension. Circulation. 2007;115(6):73342. doi: 10.1161/CIRCULATIONAHA.106.623538. [PubMed:17283267].

8. Rosner MH, Okusa MD. Acute kidney injury associated with cardiac surgery. Clin J Am Soc Nephrol. 2006;1(1):19-32. doi: 10.2215/CJN.00240605. [PubMed: 17699187].

9. Carmona P, Paredes F, Mateo E, Mena-Duran AV, Hornero F, MartinezLeon J. Is off-pump technique a safer procedure for coronary revascularization? A propensity score analysis of 20 years of experience. Interact Cardiovasc Thorac Surg. 2016;22(5):612-8. doi:10.1093/icvts/ivw005. [PubMed: 26888744].

10. Cheungpasitporn W, Thongprayoon C, Kittanamongkolchai W, Srivali N, O. Corragain OA, Edmonds PJ, et al. Comparison of Renal Outcomes in Off-Pump Versus On-Pump Coronary Artery Bypass Grafting: A Systematic Review and Meta-analysis of Randomized Controlled Trials. Nephrology (Carlton). 2015 doi: 10.1111/nep.12506. [PubMed: 25968971].

11. Hix JK, Thakar CV, Katz EM, Yared JP, Sabik J, Paganini EP. Effect of offpump coronary artery bypass graft surgery on postoperative acute kidney injury and mortality. Crit Care Med. 2006;34(12):2979-83. doi: 10.1097/01.CCM.0000248905.67352.BA. [PubMed: 17075372].
12. Xu J, Jiang W, Fang Y, Teng J, Ding X. Management of Cardiac SurgeryAssociated Acute Kidney Injury. Contrib Nephrol. 2016;187:131-42. doi: 10.1159/000443011. [PubMed: 26881864].

13. Klinkner G, Murray M. Clinical nurse specialists lead teams to impact glycemic control after cardiac surgery. Clin Nurse Spec. 2014;28(4):240-6. doi: 10.1097/NUR.0000000000000056. [PubMed: 24911825].

14. Izutani H. [Important role of a nurse parctitioner-like specialized registered nurse in a cardiac surgery team]. Nihon Geka Gakkai Zasshi. 2012;113(6):529-31. [PubMed: 23330465].

15. Murphy GJ, Ascione R, Angelini GD. Coronary artery bypass grafting on the beating heart: surgical revascularization for the next decade? Eur Heart J. 2004;25(23):2077-85. doi: 10.1016/j.ehj.2004.09.022. [PubMed: 15571822].

16. Cooley DA. Con: beating-heart surgery for coronary revascularization: is it the most important development since the introduction of the heart-lung machine?. Ann Thorac Surg. 2000;70(5):1779-81. [PubMed: 11093551].

17. Lushaj EB, Schreiner A, Jonuzi B, Badami A, DeOliveira N, Lozonschi L. Short-term clinical outcomes after off-pump coronary artery bypass grafting at a single Veterans Affairs Medical Center.JCardiothorac Surg. 2016;11(1):83. doi:10.1186/s13019-016-0480-5. [PubMed: 27185173].

18. Nardi P, Pellegrino A, Bassano C, Mani R, Chiariello GA, Zeitani J, et al. The fate at mid-term follow-up of the on-pump vs. off-pump coronary artery bypass grafting surgery. J Cardiovasc Med (Hagerstown). 2015;16(2):125-33. doi: 10.2459/JCM.0000000000000041. [PubMed: 25022926].

19. Puskas JD, Williams WH, Mahoney EM, Huber PR, Block PC, Duke PG, et al. Off-pump vs conventional coronary artery bypass grafting: early and 1-year graft patency, cost, and quality-of-life outcomes: a randomized trial.JAMA. 2004;291(15):1841-9. doi:10.1001/jama.291.15.1841. [PubMed: 15100202].

20. Palmer G, Herbert MA, Prince SL, Williams JL, Magee MJ, Brown $\mathrm{P}$, et al. Coronary Artery Revascularization (CARE) registry: an observational study of on-pump and off-pump coronary artery revascularization. Ann Thorac Surg. 2007;83(3):986-91. doi: 10.1016/j.athoracsur.2006.10.057. [PubMed: 17307446] discussion 991-2.

21. Potger KC, McMillan D, Southwell J, Connolly T, Smith KK, Ambrose M. Transfusion and bleeding in coronary artery bypass grafting: an on-pump versus off-pump comparison. J Extra Corpor Technol. 2007;39(1):24-30. [PubMed:17486870].

22. Scott BH, Seifert FC, Grimson R. Blood transfusion is associated with increased resource utilisation, morbidity and mortality in cardiac surgery. Ann Card Anaesth. 2008;11(1):15-9. [PubMed: 18182754].

23. Yu HY, Wu IH, Chen YS, Chi NH, Hsu RB, Tsai CH, et al. Comparison of outcome of off-pump coronary artery bypass surgery and conventional coronary artery bypass surgery. J Formos Med Assoc. 2003;102(8):556-62. [PubMed:14569321].

24. Hung M, Besser M, Sharples LD, Nair SK, Klein AA. The prevalence and association with transfusion, intensive care unit stay and mortality of pre-operative anaemia in a cohort of cardiac surgery patients. Anaesthesia. 2011;66(9):812-8. doi: 10.1111/j.1365-2044.2011.06819.x. [PubMed: 21790520].

25. Tsai LL, Jensen HA, Thourani VH. Intensive Glycemic Control in Cardiac Surgery. Curr Diab Rep. 2016;16(4):25. doi:10.1007/s11892-016-07195. [PubMed: 26879308].

26. Greco G, Ferket BS, D’Alessandro DA, Shi W, Horvath KA, Rosen A, et al Diabetes and the Association of Postoperative Hyperglycemia With Clinical and Economic Outcomes in Cardiac Surgery. Diabetes Care. 2016;39(3):408-17. doi:10.2337/dc15-1817. [PubMed: 26786574].

27. Knapik P, Urbanska E, Knapik M, Herdynska M, Foremny J, Zembala M. Remifentanil and fentanyl during induction of anaesthesia for coronary artery surgery. Eur J Anaesthesiol. 2006;23(Supplement 38):26. doi: 10.1097/00003643-200605001-00075. 
28. Bucerius J, Gummert JF, Walther T, Doll N, Falk V, Onnasch JF, et al. Impact of diabetes mellitus on cardiac surgery outcome. Thorac Cardiovasc Surg. 2003;51(1):11-6. doi: 10.1055/s-2003-37280. [PubMed: 12587082].

29. Azarfarin R, Alizadeh Asl A. Prevalence and intensity of hyperglycemia in non-diabetic patients undergoing coronary artery bypass graft surgery with and without cardiopulmonary bypass. Saudi Med J. 2008;29(9):1294-8. [PubMed: 18813415].

30. Mehta RL, Kellum JA, Shah SV, Molitoris BA, Ronco C, Warnock DG, et al. Acute Kidney Injury Network: report of an initiative to improve outcomes in acute kidney injury. Crit Care. 2007;11(2):R31. doi: 10.1186/cc5713. [PubMed: 17331245].

31. Di Mauro M, Gagliardi M, Iaco AL, Contini M, Bivona A, Bosco P, et al. Does off-pump coronary surgery reduce postoperative acute renal failure? The importance of preoperative renal function. Ann Thorac Surg. 2007;84(5):1496-502. doi: 10.1016/j.athoracsur.2007.05.054. [PubMed: 17954051].

32. Abu-Omar Y, Mussa S, Naik MJ, MacCarthy N, Standing S, Taggart DP. Evaluation of Cystatin $C$ as a marker of renal injury following on-pump and off-pump coronary surgery. Eur J Cardiothorac Surg. 2005;27(5):893-8. doi:10.1016/j.ejcts.2004.12.063. [PubMed: 15848332].

33. Kerendi F, Morris CD, Puskas JD. Off-pump coronary bypass surgery for high-risk patients: only in expert centers?. Curr Opin Cardiol. 2008;23(6):573-8. doi: 10.1097/HCO.0b013e328312c311. [PubMed: 18830072].

34. Hussain I, Ghaffar A, Shahbaz A, Sami W, Muhammad A, Seher N, et al. In hospital outcome of patients undergoing coronary endarterectomy: comparison between off-pump vs on pump CABG. J Ayub Med Coll Abbottabad. 2008;20(1):31-7. [PubMed: 19024182].

35. Lamy A, Farrokhyar F, Kent R, Wang X, Smith KM, Mullen JC, et al. The
Canadian off-pump coronary artery bypass graft registry: a one-year prospective comparison with on-pump coronary artery bypass grafting. Can J Cardiol. 2005;21(13):1175-81. [PubMed: 16308593]

36. Jones KW, Cain AS, Mitchell JH, Millar RC, Rimmasch HL, French TK, et al. Hyperglycemia predicts mortality after CABG: postoperative hyperglycemia predicts dramatic increases in mortality after coronary artery bypass graft surgery. J Diabetes Complications. 2008;22(6):36570. doi: 10.1016/j.jdiacomp.2007.05.006. [PubMed: 18413193].

37. Mishra M, Malhotra R, Karlekar A, Mishra Y, Trehan N. Propensity casematched analysis of off-pump versus on-pump coronary artery bypass grafting in patients with atheromatous aorta. Ann Thorac Surg. 2006;82(2):608-14. doi: 10.1016/j.athoracsur.2006.03.071. [PubMed: 16863772].

38. van Straten AH, Bekker MW, Soliman Hamad MA, van Zundert AA, Martens EJ, Schonberger JP, et al. Transfusion of red blood cells: the impact on short-term and long-term survival after coronary artery bypass grafting, a ten-year follow-up. Interact Cardiovasc Thorac Surg. 2010;10(1):37-42. doi: 10.1510/icvts.2009.214551. [PubMed: 19815567].

39. Wijeysundera DN, Beattie WS, Djaiani G, Rao V, Borger MA, Karkouti $\mathrm{K}$, et al. Off-pump coronary artery surgery for reducing mortality and morbidity: meta-analysis of randomized and observational studies. J Am Coll Cardiol. 2005;46(5):872-82. doi: 10.1016/j.jacc.2005.05.064. [PubMed: 16139139].

40. Sajja LR, Mannam G, Sompali S, Reddy KV, Ravirala BR, Raju BS, et al. Does multi-vessel off-pump coronary artery bypass grafting reduce post operative morbidity compared to on-pump CABG?. Indian J Thorac Cardiovasc Surg. 2004;20(4):173-7. doi:10.1007/s12055-004-0080-1.

41. Guler M, Kirali K, Toker ME, Bozbuga N, Omeroglu SN, Akinci E, et al. Different CABG methods in patients with chronic obstructive pulmonary disease. Ann Thorac Surg. 2001;71(1):152-7. [PubMed: 11216737]. 